\title{
VECTORIAL COMMAND OF INDUCTION MOTOR PUMPING SYSTEM SUPPLIED BY A PHOTOVOLTAIC GENERATOR
}

\author{
Messaoud Makhlouf — Feyrouz Messai — Hocine Benalla *
}

\begin{abstract}
With the continuous decrease of the cost of solar cells, there is an increasing interest and needs in photovoltaic (PV) system applications following standard of living improvements. Water pumping system powered by solar-cell generators are one of the most important applications. The fluctuation of solar energy on one hand, and the necessity to optimise available solar energy on the other, it is useful to develop new efficient and flexible modes to control motors that entrain the pump. A vectorial control of an asynchronous motor fed by a photovoltaic system is proposed. This paper investigates a photovoltaic-electro mechanic chain, composed of a PV generator, DC-AC converter, a vector controlled induction motor and centrifugal pump. The PV generator is forced to operate at its maximum power point by using an appropriate search algorithm integrated in the vector control. The optimization is realized without need to adding a DC-DC converter to the chain. The motor supply is also ensured in all insolation conditions. Simulation results show the effectiveness and feasibility of such an approach.

K e y w ords: solar energy, optimization, photovoltaic generator, pumping, modelling, efficiency
\end{abstract}

\section{INTRODUCTION}

The increasing of the world energy demand, due to the modern industrial society and population growth, is motivating a lot of investments in alternative energy solutions, in order to improve energy efficiency and power quality issues. The use of photovoltaic energy is considered to be a primary resource, because there are several countries located in tropical and temperate regions, where the direct solar density may reach up to $1000 \mathrm{~W} / \mathrm{m}$. One of the most popular applications of the photovoltaic energy utilization is the water pumping system driven by electrical motors. The two main restrictions for using solar energy are the high initial installation cost and the very low photovoltaic cell conversion efficiency. The cell conversion ranges vary from $12 \%$ of efficiency up to a maximum of $29 \%$ for very expensive units [1]. In spite of those facts, there has been a trend in price decreasing for modern power electronics systems and photovoltaic cells, indicating good promises for new installations. Moreover, the maximum power of a photovoltaic system changes with solar intensity, and temperature; and dynamic loads influence the performance by changing continuously the operating point. In order to amortize the initial investments, it is very important to optimize the photovoltaic water pumping system, by the use of power electronics converters to adapt dynamically the electrical impedance to the PVG for different operating conditions $[2,3]$. Various studies have been carried out on sizing $[4,5]$, matching $[6,7]$ and optimizing PV systems [8]. DC motors were initially used since they offered easy implementation with cheap power conversion $[9,10]$. A number of existing operational pumping systems have shown that these schemes suffer from maintenance problems. To overcome this drawback, brushless permanent magnet motors have been proposed [11]. How ever, this solution is limited only for Low power PV systems. The induction motor based PV pumping systems offers an Alternative for a more reliable and maintenance free system [12]. The motor characteristics are severely affected by the PVG which was considered as a current generator with dependent voltage source. For such applications, where the PV water pumping system is driven by an AC motor (PMSM or IM), a chopper and/or an inverter should be included in order to perform the DC-AC conversion stage. For PV water pumping systems, two types of pumps are widely used: the volumetric pump and the centrifugal pump. It is found that the PVG energy utilized by the centrifugal pump is much higher than by the volumetric pump. In fact, in the case of the centrifugal pumps, the operation takes place for longer periods even for low insulation levels, and the load characteristic is in closer proximity to the PVG maximum power locus. In PV water pumping systems, the maximum power point tracking (MPPT) is usually used as online control strategy to track the maximum output power operating point of the PVG for different operating conditions of insolation and temperature of the PVG. Different optimization strategies have been proposed to improve the over all system efficiency .In this paper a vectoriel control method has been proposed to ensure the optimization of the whole system showed in Fig. 1. Allowing the improvement of the efficiency maximization.

\section{PHOTOVOLTAIC GENERATOR MODEL}

The direct conversion of the solar energy into electrical power is obtained by solar cells. A PVG is composed by many strings of solar cells in series, connected in parallel, in order to provide the desired values of output voltage

\footnotetext{
* Department of Electrical Engineering, Faculty of Engineering Sciences, Mentouri University of Constantine, Algeria m_makhlouf@hotmail.com
} 


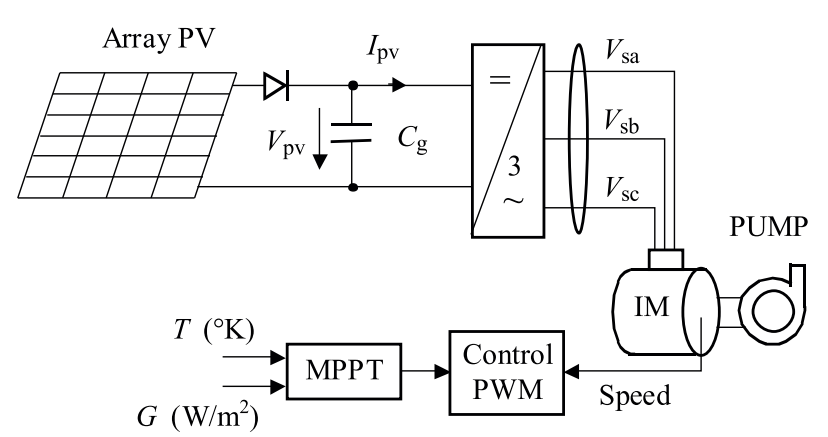

Fig. 1. Block diagram of the global system

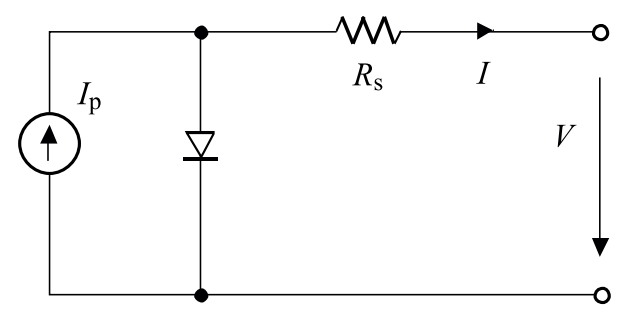

Fig. 2. Solar-cell equivalent circuit

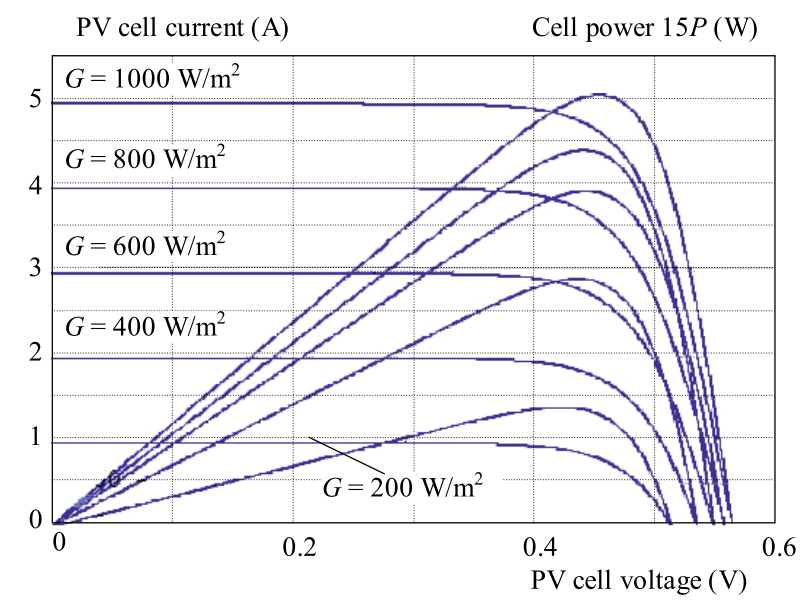

Fig. 3. Characteristics of a solar-cell generator

and current. Figure 2 shows the equivalent circuit of a PVG, from which non linear $I-V$ characteristic can be deduced.

The cells are connected in series and in parallel combinations in order to form an array of the desired voltage and power levels. Figure 3 represents the $I-V$ and $P-V$ characteristics of the solar-cell generator for five insolation levels (in percentages).

Applying Kirchhoff law of current, the terminal current of the cell is:

$$
I=I_{L}-I_{D}
$$

The light current is related to irradiance and temperature and the light current measured at some reference conditions:

$$
I_{L}=\frac{G}{G_{r e f}}\left(I_{L, r e f}+\mu_{I s c}\left(T_{c}-T_{c, r e f}\right)\right)
$$

where: $I_{L, r e f}$ - is the Light current at reference conditions (A), $G, G_{r e f}$ is the actual and the reference irradiance $\left(\mathrm{W} / \mathrm{m}^{2}\right), T, T_{c, r e f}$ - is the cell temperature, actual and at reference condition $\left({ }^{\circ} \mathrm{K}\right)$, and $\mu_{I s c}$-is the manufacturer supplied temperature coefficient of short circuit current $\left(\mathrm{A} /{ }^{\circ} \mathrm{K}\right)$.

The diode current is given by Shockley equation

$$
I_{D}=I_{0}\left[\exp \frac{q\left(V+I R_{s}\right)}{\gamma k T_{c}}-1\right]
$$

where: $V$ - is the terminal voltage $(\mathrm{V}), I$-is the reverse saturation current (A), $\gamma$ - is the shape factor, $R_{s}$ - is the series resistance $(\Omega), q$-is the electron charge $1.602 \times 10^{-19} \mathrm{C}$, and $k$-is the Boltzman constant $=$ $1.381 \times 10^{-23} \mathrm{~J} / \mathrm{K}$.

The reverse saturation current is

$$
I_{0}=D T_{c}^{3} \exp \frac{-q \varepsilon_{G}}{A k T_{c}}
$$

where $D$ - is the diode diffusion factor, $\varepsilon_{G}$ - is the material band gap energy (1.12 eV for $\mathrm{Si}, 1.35 \mathrm{eV}$ for GaGs), and $A$ - is the completion factor.

The reverse saturation current is actually computed by taking the ratio of equation (2.4) at two different temperatures, thereby eliminating $D$, similar to the determination of $I_{L}, I_{0}$ is related to the temperature and the saturation current estimated at some reference conditions

$$
I_{0}=I_{0, r e f}\left(\frac{T_{c}}{T_{c, \text { ref }}}\right)^{3} \exp \left[\frac{q \varepsilon_{G}}{k A}\left(\frac{1}{T_{c, r e f}}-\frac{1}{T_{c}}\right)\right] .
$$

Thus the $I-V$ characteristic is described by

$$
I=I_{L}-I_{0}\left(\exp \frac{q\left(V+I R_{s}\right)}{\gamma k T_{c}}-1\right) .
$$

The shape factor $\gamma$ is a measure of cell temperature and is related to the completion factor as

$$
\gamma=A N_{c s} N_{s},
$$

where $N_{c s}$ is the number of cells connected in series per module. A module is defined as an array of cells, usually encapsulated for protection, as it is supplied by manufacturer; $N_{s}$ is the number of modules connected in series of the entire array. While $R_{s}$ and $\gamma$ are assumed to be constant, $I_{L}$ is a function of irradiance and cell temperature and $I_{0}$ is a function of temperature only. The cell temperature can be determined from the ambient temperature and with the help of some standard test information. In [13] the way to Evaluate this parameters based on the four parameters model proposed by Townsend (1989), Eckstein (1990) and Fry, Bryan (1998) to be the most precise model that good produced the $I-V$ characteristics. 
Now only the four parameters $I_{L}, I_{0}, R s$ and $\gamma$ need to be evaluated, a method to calculate these parameters has been developed by Eckstein [2], Duffie and Beckman [1]. Since there are four unknown parameters, four conditions of the current I and the voltage V are needed. Generally, available manufacturers information are set at three points at the reference conditions, $\left(G=1000 \mathrm{~W} / \mathrm{m}^{2}\right.$, $T=25{ }^{\circ} \mathrm{C}$ ) the voltage at open circuit $V_{o c, r e f}$, the current at short circuit $I_{s c \text {,ref }}$ and the voltage and current at maximum power $V_{m p, r e f}$ and $I_{m p, r e f}$.

The 4th condition comes from the knowledge of the temperature coefficients at short circuit $\mu_{I_{s c}}$ and at open circuit $\mu_{V_{o c}}$.

$$
\begin{gathered}
I_{m p, r e f}=I_{s c, r e f}-I_{0, r e f} \times \\
\exp \left(\frac{V_{t}}{\left.V_{m p, r e f}+I_{m p, r e f} R_{s}\right)}\right), \\
0=I_{s c, r e f}-I_{0, r e f} \exp \left(\frac{V_{t}}{V_{o c, r e f}}\right), \\
I_{L, \text { ref }} \approx I_{s c, r e f} .
\end{gathered}
$$

Substituting equation (2.7) into equation (2.9) and solving for $\gamma$ and $I_{0, \text { ref }}$ gives

$$
\begin{gathered}
I_{0, r e f}=I_{s c, r e f} \exp \left(-\frac{V_{t}}{V_{o c, r e f}}\right) \\
\gamma_{r e f}=\frac{q\left(V_{m p, r e f}+R_{s} I_{m p, r e f}-V_{o c, r e f}\right)}{K T_{c, r e f} \ln \left(1-\frac{I_{m p, r e f}}{I_{s c, r e f}}\right)} .
\end{gathered}
$$

The indices oc, $s c, m p$ and ref refer to the open circuit, the short circuit, the maximum power and the reference condition respectively.

The cell parameters change with the solar radiation $G\left(\mathrm{~W} / \mathrm{m}^{2}\right)$ and ambient temperature $T\left({ }^{\circ} \mathrm{K}\right)$ and they can be estimated by the following relations

$$
\begin{gathered}
I_{L}=\left(G / G_{r e f}\right)\left(L_{L, r e f}+\mu_{I s c}\left(T_{c}-T_{r e f}\right)\right. \\
I_{O}=I_{0, r e f}\left(T / T_{r e f}\right)^{3} \exp \left(\frac{N_{s} E_{q}}{A}\left(1-\frac{T_{c, r e f}}{T_{c}}\right)\right) \\
\gamma=\gamma_{r e f}\left(T_{c} / T_{c, r e f}\right)
\end{gathered}
$$

\subsection{Inverter model}

A natural PWM switching technique is used to drive the DC-AC inverter with a modulation index $M$ and the ratio between the frequencies of the carrier and modulating waveforms $P$. It can be shown from Murphy and Turnbull [7] that in the case of a full bridge control and for $P>9$, the rms value of the fundamental motor voltage $V_{m}$ is given by

$$
V_{m}=\frac{M V}{\sqrt{2}} .
$$

For the case studied in Yao et al[14], the modulation index is set to: $M=0.8$.

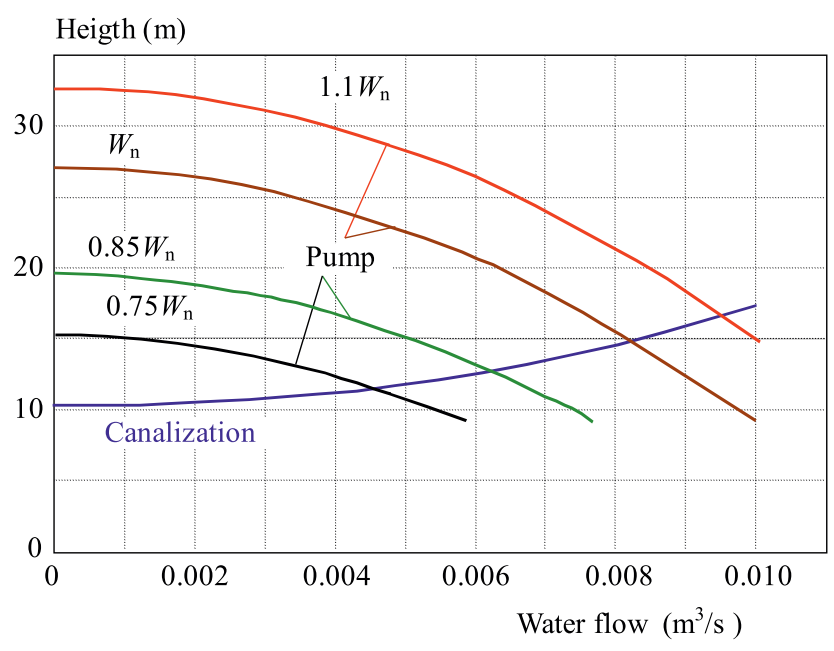

Fig. 4. $H(Q)$ Characteristic

\section{INDUCTION MOTOR MODEL}

The mathematical dynamic model of the asynchronous motor is described in $[6,20]$ by the following equations

$$
\begin{aligned}
\frac{\mathrm{d} I_{s d}}{\mathrm{~d} t}= & \frac{1}{\sigma L_{s}}\left[-\left(R_{a}+\frac{M^{2} R_{r}}{L_{r}^{2}}\right) I_{s d}+\omega_{s} \sigma L_{s} I_{s q}+\right. \\
& \left.\frac{M R_{r}}{L_{r}} \Phi_{r d}+\frac{M}{L_{r}} \omega_{m} \Phi_{r q}+v_{s d}\right] \\
\frac{\mathrm{d} I_{s q}}{\mathrm{~d} t}= & \frac{1}{\sigma L_{s}}\left[-\left(R_{a}+\frac{M^{2} R_{r}}{L_{r}^{2}}\right) I_{s q}-\frac{M}{L_{r}} \omega_{m} \Phi_{r d}+\right. \\
& \left.\frac{M R_{r}}{L_{r}} \Phi_{r q}-\sigma \omega_{s} L_{s} I_{s d}+v_{s d}\right], \\
\frac{\mathrm{d} \Phi_{r d}}{\mathrm{~d} t}= & \frac{-R_{r}}{L_{r}} \Phi_{r d}+\left(\omega_{s}-\omega_{m}\right) \Phi_{r q}+\frac{M R_{r}}{L_{r}} I_{s d} \\
\frac{\mathrm{d} \Phi_{r q}}{\mathrm{~d} t}= & \frac{-R_{r}}{L_{r}} \Phi_{r q}+\left(\omega_{s}-\omega_{m}\right) \Phi_{r d}+\frac{M R_{r}}{L_{r}} I_{s q} .
\end{aligned}
$$

In this case, the induction motor develops an electromagnetic torque $T_{e}$ expressed as follows

$$
T_{e}=\frac{M p}{L_{r}}\left(I_{s q} \Phi_{r d}-I_{s d} \Phi_{r q}\right)
$$

$d, q$ : axes corresponding to the asynchronous reference axes in Park model $L_{s}, L_{r}, R_{a}, R_{r}$ and $M$ are: stator and rotor main inductances, resistances and mutual inductance respectively. $J$ is the rotor inertia moment, $\sigma$ dispersion factor. $I_{s d}, \Phi_{r d}, I_{s q}, \Phi_{r q}$ are $d$-axis stator current, rotor flux and $q$-axis stator current, rotor flux, and $p$ is the number of pole pairs, $\omega_{s}$ and $\omega_{m}$ are the angular speed of the rotating magnetic and electric fields respectively. 


\section{CENTRIFUGAL PUMP MODEL}

The head-Flowrate $h-Q$ characteristic of a mono cellular centrifugal pump is Obtained using PfleiderPeterman model $[15,16]$ : The multi speed family headcapacity Curves are shown in Fig. 4. And can be expressed approximately by the following Quadratic form

$$
H=a_{0} \omega^{2}-a_{1} \omega Q-a_{2} Q^{2} .
$$

Where $a_{0}, a_{1}, a_{2}$ are the coefficients generally given by the manufacturers.

The hydraulic power, resistive torque and the mechanic power are given by

$$
P_{H}=\rho g Q H, \quad T_{r}=k_{r} \omega^{2}+C_{s} .
$$

The pump efficiency is defined as the ratio of the hydraulic power imparted by the Pump to the fluid to the shaft mechanical power and is given by

$$
\eta_{p}=\frac{\rho_{H} g H Q}{C\left(1-\frac{\omega_{S l}}{\omega_{S}}\right)^{3} \omega_{S}}
$$

where $Q, H, \rho, g, \omega_{S}$ and $\omega_{S l}$ are the water flow $\left(\mathrm{m}^{3} / \mathrm{sec}\right)$, the total height of the well $(\mathrm{m})$, the density $\left(\mathrm{Kg} / \mathrm{m}^{2}\right)$ and the gravity $\left(\mathrm{m} / \mathrm{s}^{2}\right)$, the angular frequency of the supply $(\mathrm{rad} / \mathrm{s})$ and the slip speed $(\mathrm{rad} / \mathrm{s})$, respectively.

\section{VECTORIAL COMMAND APPROACH}

The vector control is based on the field-oriented control method. For the regulation of the main variables (current, flux, speed) to their reference values, regulators were used of the type PI.

So we have as interest to keep only the $d$ axis flux component, and that means to oblige the $q$ axis flux component to be zero. The torque will be reduced then to

$$
T_{e}=p \frac{M}{L_{r}}\left(\Phi_{r d} I_{s q}\right) .
$$

Therefore the $d$ and $q$ axis statoric voltages equations will be

$$
\begin{aligned}
v_{s d}= & \left(R_{s}+\frac{R_{r} M^{2}}{L_{r}^{2}}\right) I_{s d} \\
& +L_{s} \sigma \frac{\mathrm{d} I_{s d}}{\mathrm{~d} t}-\omega_{s} L_{s} I_{s q}-\frac{R_{r} M}{L_{r}^{2}} \Phi_{r d}, \\
v_{s q}= & R_{s} I_{s q}+L_{s} \sigma \frac{\mathrm{d} I_{s q}}{\mathrm{~d} t}+\omega_{s} L_{s} \sigma I_{s d}+\omega_{s} \frac{M}{L_{R}} \phi_{s d} .
\end{aligned}
$$

The compensation has as objective to uncouple the two $d$ and $q$ axis voltages and currents. Under such conditions, the system becomes linear like in case of DC motor. Thus we have [17], [18]

$$
v_{s d}+v_{s d c}=v_{s d 1}, \quad v_{s q}+v_{s q c}=v_{s q 1}
$$

where

$$
\begin{aligned}
& v_{s q c}=-\omega_{s} L_{s} \sigma I_{s q}+\omega_{s} \frac{M}{L_{R}} \Phi_{r d}, \\
& v_{s d c}=-\omega_{s} L_{s} \sigma I_{s d}+\omega_{s} \frac{M}{L_{R}} \Phi_{r q},
\end{aligned}
$$

are the compensation voltages.

The transfer functions of the plant for the controllers of the vector-controlled induction motor drives can be derived as shown in [19].

Speed and $\Phi_{r d}$ Flux controllers:

$$
\begin{aligned}
G_{w m} & =\frac{\omega_{m}}{T_{e}}=\frac{1}{J s+f}, \\
G_{\Phi_{r d}} & =\frac{\Phi_{r d}}{i_{s d}}=\frac{1}{M+T_{r} s} .
\end{aligned}
$$

$I_{s d}$ and $I_{s q}$ Current controllers:

$$
\begin{aligned}
G_{i s d} & =\frac{i_{s d}}{V_{s d 1}}=\frac{1}{R_{a}+\sigma L_{s} s}, \\
G_{i s q} & =\frac{i_{s q}}{V_{s q 1}}=\frac{1}{R_{a}+\sigma L_{s} s},
\end{aligned}
$$

where $S$ is the Laplace operator.

Based on those equations and after some algebra we obtain PI parameters for speed, flux and current (Table 1 ), where $f f$ - is the viscosity coefficient of the induction motor. After $\omega_{n}$ is obtained upon calculation of the transfer function of a closed loop, parameters $K_{i}$ and $K_{p}$ are identified from comparison with a general second order equation $\frac{1}{1+\frac{2 \xi}{\omega_{n}} s+\frac{s^{2}}{\omega_{n}^{2}}}$.

\section{LOCATION OF MAXIMUM POWER POINT}

At the maximum power point we have

$$
\frac{\partial P}{\partial V}=V \frac{\partial I}{\partial V}+I=0 \text {. }
$$

With the current described by equation (1.6), the partial derivative of $\mathrm{I}$ with respect to $V$ is

$$
\frac{\partial I}{\partial V}=-I_{0} \exp \frac{q\left(V+I R_{S}\right)}{k T_{c, r e f} \gamma} \frac{q}{k T_{c, r e f}}\left(1+R_{S} \frac{\partial I}{\partial V}\right) \text {. }
$$

An explicit expression for $\frac{\partial I}{\partial V}$ is obtained simply by rearranging the equation. Back substitution of this explicit expression (3.15) and using $I_{m p}$ for $I$ and $V_{m p}$ for $V$ gives:

$$
\begin{aligned}
& I_{L}+I_{0} \exp \frac{q\left(V_{m p}+I_{m p} R_{S}\right)}{k T_{c, r e f}} \times \\
& \left(1+\frac{\frac{q V_{m p}}{k T_{c, r e f} \gamma}}{1+\frac{q R_{S} I_{0}}{k T_{c, r e f} \gamma} \exp \frac{q\left(V_{m p}+I_{m p} R_{S}\right)}{k T_{c, r e f} \gamma}}\right)=0 .
\end{aligned}
$$


Table 1. PI Regulator Coefficients

\begin{tabular}{ccc}
\hline Coefficients & $K_{i}$ & $K_{p}$ \\
\hline Speed & $J \omega_{s}^{2}$ & $2\left(\xi \omega_{n}-f f\right) / p$ \\
Flux & $2 \omega_{n}^{2} L_{r} / R_{r} M$ & $2 \omega_{n} L_{r}-/ R_{r} M$ \\
Current & $\sigma L_{S} \omega_{n}^{2}$ & $2 L_{S} \xi \sigma \omega_{n}-\left(R_{a}+R_{r}\left(\frac{M}{L-r}\right)^{2}\right)$ \\
\hline
\end{tabular}

Table 2. Error Estimation between the system before and after optimization

\begin{tabular}{|c|c|c|c|c|c|c|c|c|c|c|c|c|}
\hline \multirow[b]{2}{*}{$\begin{array}{c}G \\
\left(\mathrm{~W} / \mathrm{m}^{2}\right)\end{array}$} & \multicolumn{4}{|c|}{ Non Optimized Results } & \multicolumn{4}{|c|}{ Optimized Results } & \multicolumn{4}{|c|}{ Relative Error (\%) } \\
\hline & $\begin{array}{c}\omega \\
(\mathrm{rad} / \mathrm{s})\end{array}$ & $\begin{array}{c}Q \\
\mathrm{~m}^{2} / \mathrm{h}\end{array}$ & $\eta \%$ & $V_{p h}$ & $\begin{array}{c}\omega \\
(\mathrm{rad} / \mathrm{s})\end{array}$ & $\begin{array}{c}Q \\
\mathrm{~m}^{2} / \mathrm{h}\end{array}$ & $\eta \%$ & $V_{p h}$ & $\begin{array}{c}\omega \\
(\mathrm{rad} / \mathrm{s})\end{array}$ & $\begin{array}{c}Q \\
\mathrm{~m}^{2} / \mathrm{h}\end{array}$ & $\eta \%$ & $V_{p h}$ \\
\hline 1000 & 180 & 6.753 & 8.21 & 20 & 180 & 6.753 & 8.755 & 200 & 0 & 0 & 6.225 & 0 \\
\hline 800 & 172.393 & 6.125 & 8.153 & 150.12 & 176.451 & 6.697 & 8.755 & 200 & 2.298 & 8.541 & 6.876 & 24.94 \\
\hline 600 & 160.110 & 5.25 & 6.667 & 116.53 & 165.02 & 5.751 & 8.753 & 200 & 2.975 & 8.711 & 23.831 & 41.735 \\
\hline 400 & 100.01 & 0 & 4.999 & 66.667 & 125.12 & 2.125 & 8.753 & 200 & 20.068 & 100 & 42.888 & 66.666 \\
\hline 200 & 59.13 & 0 & 3.672 & 55 & 82.35 & 1.376 & 8.753 & 200 & 28.19 & 100 & 58.048 & 72.5 \\
\hline
\end{tabular}

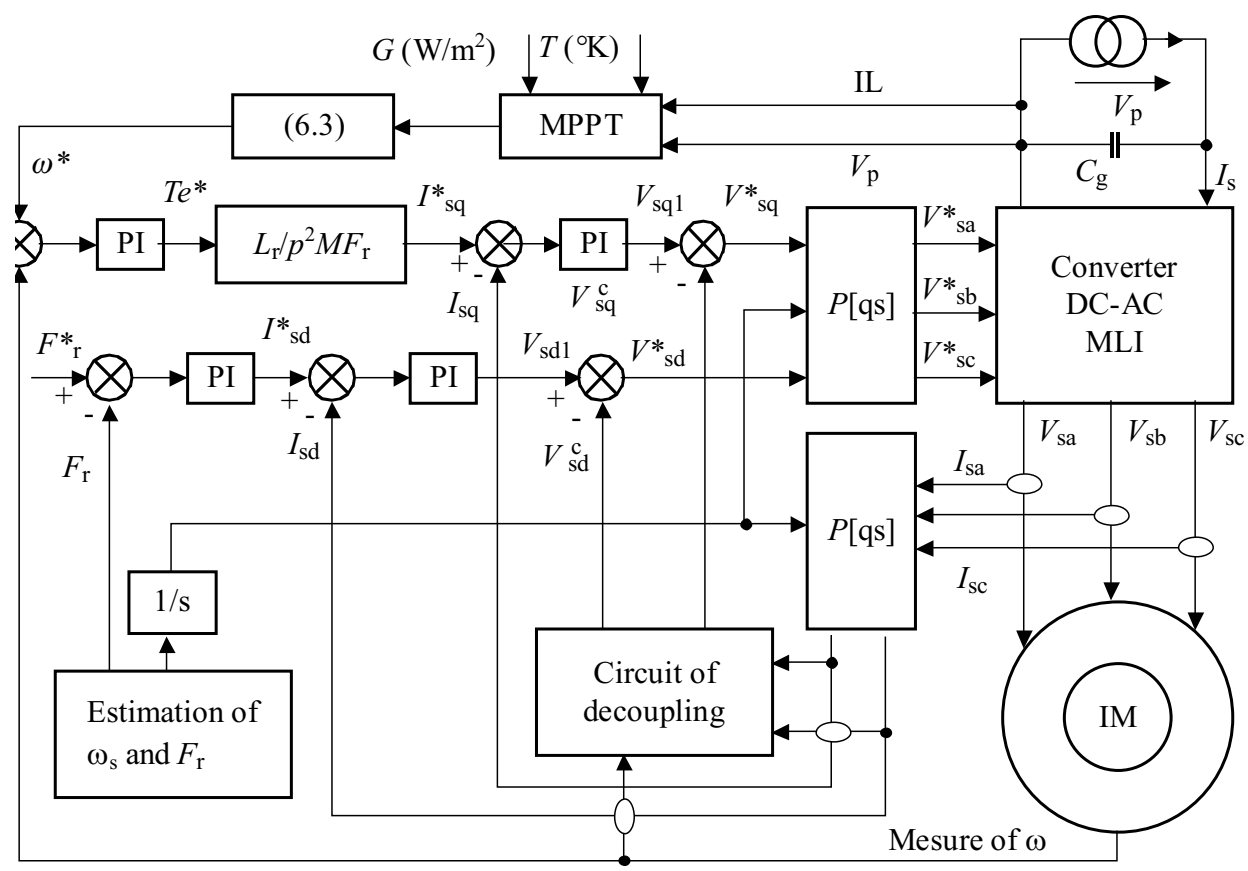

Fig. 5. The Proposed optimized method with the current sensors shown as small "ellipses"

To eliminate $V_{m p}$ in equation (6.3), the general $I-V$ equation (2.2) is used, with $I_{m p}$ substituted for $I$ and $V_{m p}$ substitutes for $V$. Rearranging to solve for $V_{m p}$ gives

$$
V_{m p}=\frac{k T_{c, r e f} \gamma}{q} \ln \left(\frac{I_{L}-I_{m p}}{I_{0}}+1\right)-I_{m p} R_{S} .
$$

An explicit expression for $I_{m p}$ is obtained by substituting equation (6.4) into equation (6.3)

$I_{m p}+\frac{\left(I_{m p}-I_{L}-I_{0}\right)\left[\ln \left(\frac{I_{L}-I_{m p}}{I_{0}}+1\right)-\frac{I_{m p} R_{S} q}{k T_{c, r e f} \gamma}\right]}{1+\left(I_{L}-I_{m p}+I_{0}\right) \frac{R_{S} q}{k T_{c, r e f}} \gamma}$

$=0$.
Newton Raphson is applied to solve for $I_{m p}$ using an initial guess given by

$I_{m p, \text { guess }}=$

$$
\frac{G}{G_{r e f}} N P\left(I_{m p, r e f}+\mu_{I s c}\left(T_{c}-T_{c, r e f}\right)\right) .
$$

Once $I_{m p}$ is found, $V_{m p}$ may be calculated using equation (6.4) and thus the current and voltage at the maximum power point is determined as a consequence the maximum power.

The centrifugal pump is more suitable for PV array powered drive system since it does not require a high motor starting torque. 


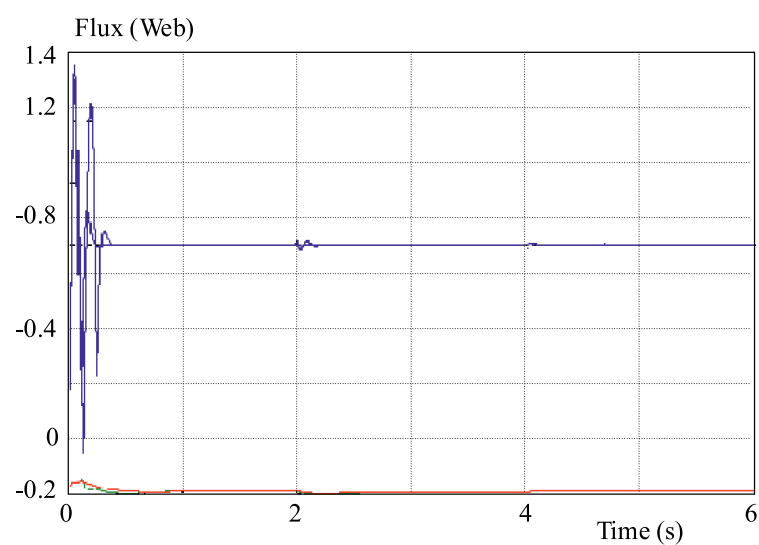

Fig. 6. $F_{r d}, F_{r q}$

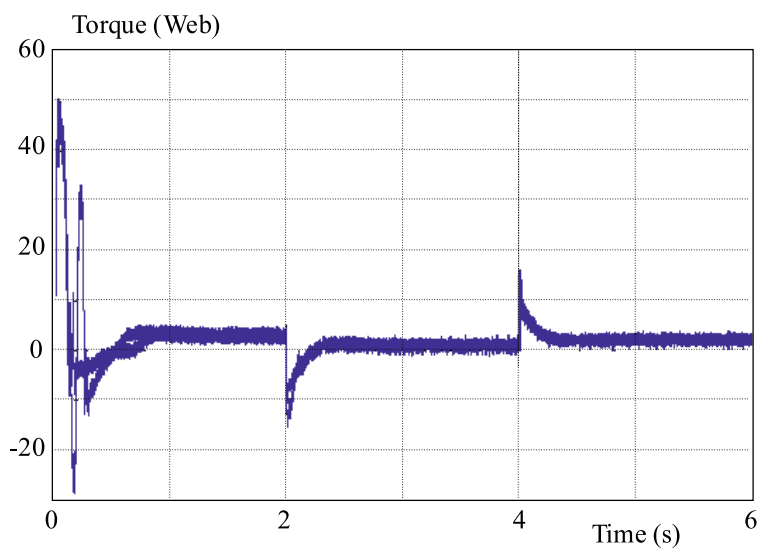

Fig. 8. Torque versus time

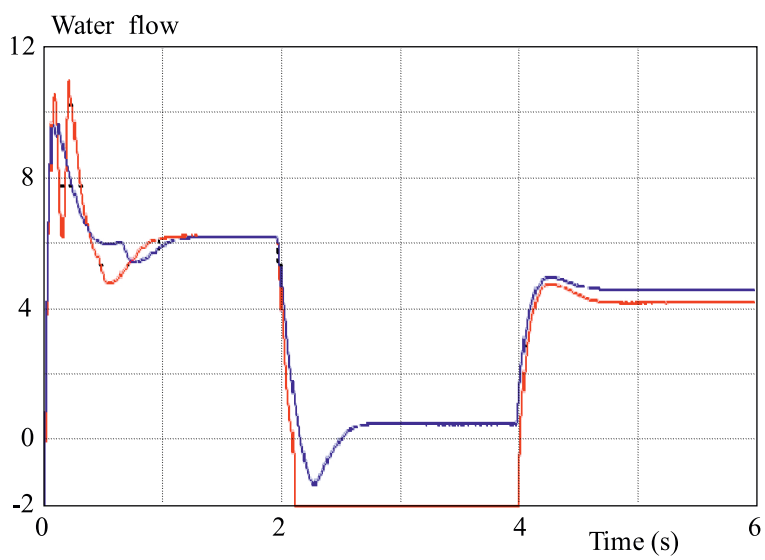

Fig. 10. Water flow rate versus time

In the optimum state we have

$$
P_{m p} \eta=K_{p} w_{o p t}^{3}
$$

where $P_{m p}, \eta$ are the maximum input power and motor efficiency. We need to know the optimum speed that makes the system more efficiency.

If the system is operating in nominal conditions of insolation and temperature, the last equation becomes

$$
P_{n} \eta=K_{p} \omega_{n}^{3}
$$

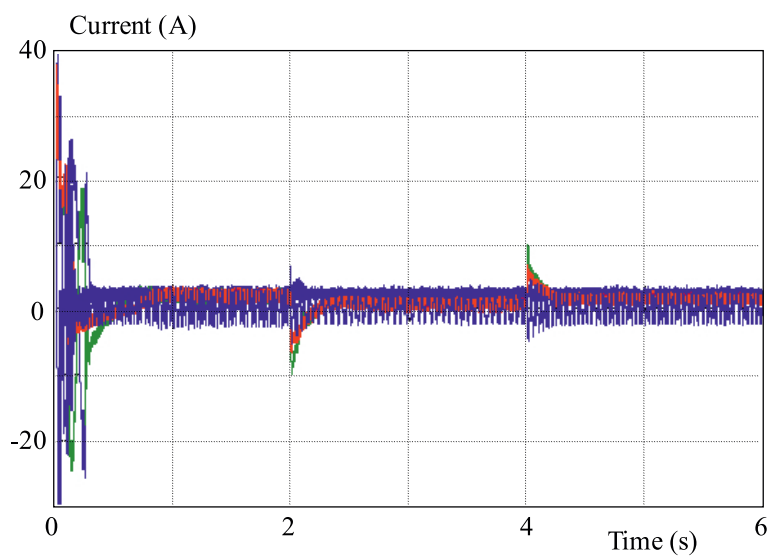

Fig. 7. $I_{s d}$ and $I_{s q}$ current axis

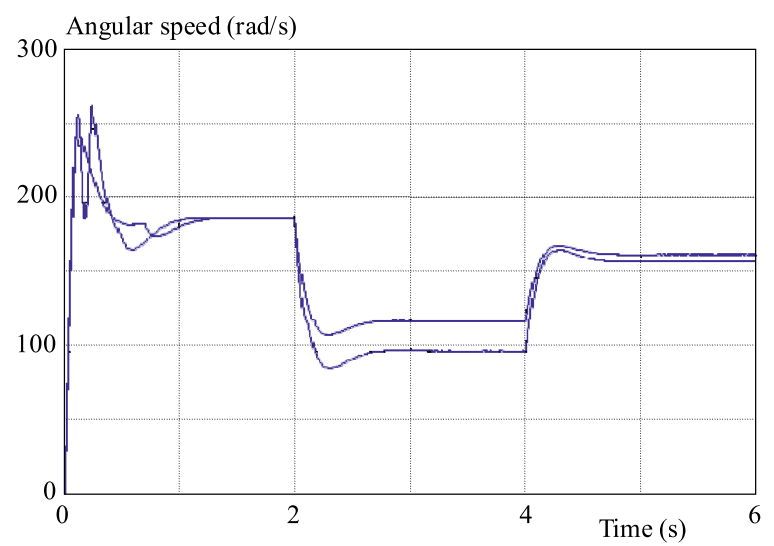

Fig. 9. Speed after and before optimization

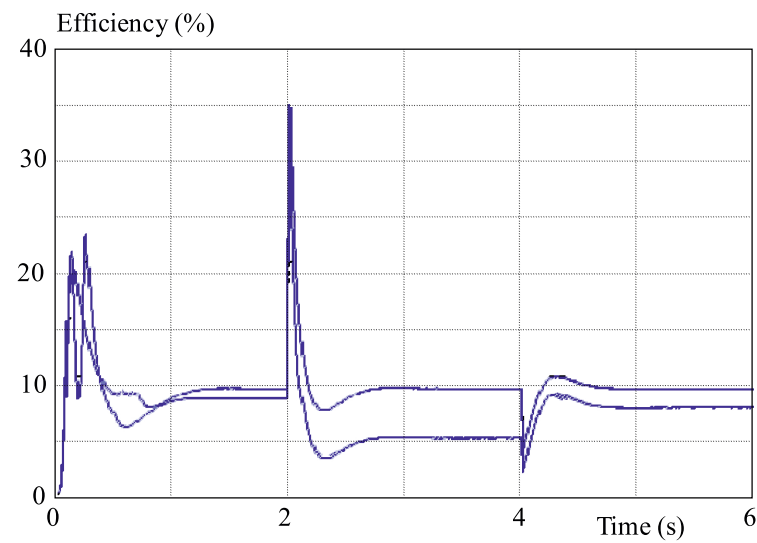

Fig. 11. Efficiency versus time

where $P_{n}, \eta, \omega_{n}$ are the nominal values of input power, speed and efficiency of the motor in nominal conditions.

From (6.7) and (6.8), we can define a new control reference speed of the inverter that allows the system to operate at its maximum power coming from the panel output as follows

$$
\omega_{o p t}=\omega_{n} \sqrt[3]{\frac{p_{n}}{p_{m p} \eta}}
$$

To reach the peak power point in order to optimize the whole system we proposed the scheme shown in Fig. 5. 


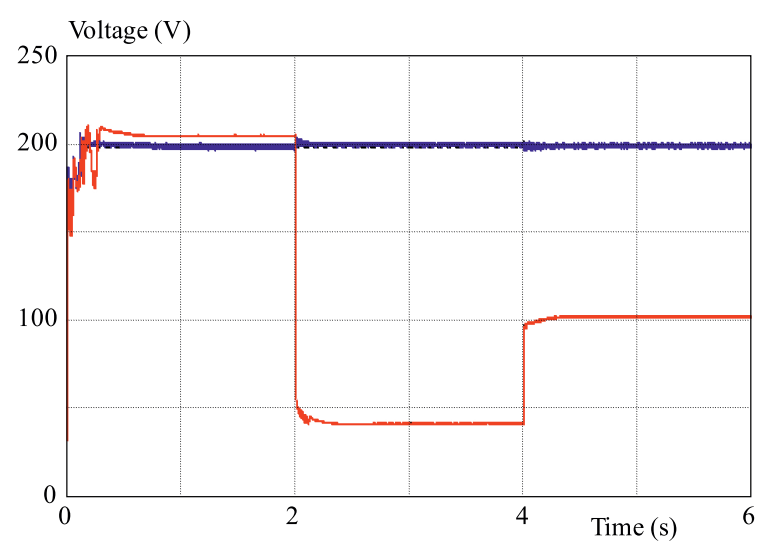

Fig. 12. Photvoltaic generator voltage before and after optimization

\section{SIMULATION RESULTS AND DISCUSSION}

In order to verify the proposed field-oriented control law, and maximum power point tracking effectiveness, digital simulations were carried out.

Notice that the flux command set point is selected at nominal value $\Phi_{r d}=0.8 \mathrm{~Wb}$ and $\Phi_{r q} \cong 0 \mathrm{~Wb}$.

Figures $6-12$ show the wave form of photovoltaic voltage, Rotor flux; and rotor speed response under the proposed controllers for three insulation levels of insulation $G=1000,350$ and $600 \mathrm{~W} / \mathrm{m}^{2}$. The waveforms depicted through this figures prove the feasibility of the Proposed scheme shown in Fig. 5. It can be seen in Fig. 6. That the flux magnitude is constantly maintained and stays at a recommended value of $0.80 \mathrm{~Wb}$. As can be seen the flux has been maintained as constant although the developed torque is Changed Fig. 8. Furthermore at the same time the rotor speed converges to its reference determined by equation (6.9).

It is important to note that even though the power provided by the photovoltaic generator is lower than its maximum this result has motivated the use of $\mathrm{DC} / \mathrm{AC}$ converter without needing to another ( $\mathrm{DC} / \mathrm{DC}$ converter) for ensuring the desired maximum power point tracking, which essentially keeps the convergence power to its optimal value.

In order to test the efficiency of the proposed method, we applied three levels of insulation just to be sure that even in rapid changing in atmospheric conditions like insulation or temperature the photovoltaic generator is able to function around the optimal value. The result of MPPT effect and the rate of difference system parameters before and after optimization is illustrated in Table 2 . On account of the availability of rotor flux estimator, the convergence of flux amplitude tracking to nominal value is perfect without any additional control. The photovoltaic voltage is maintained at it's optimum value corresponding to $200 \mathrm{~V}$ which indicated the optimal power.

One may also notice that it is very important to realize that in general the optimization methods has an important effect on the studied system especially when the photovoltaic system work away from the nominal values of insulation and temperature, in very high level of insulation (in our case $1000 \mathrm{~W} / \mathrm{m}^{2}$ ) the optimization has no effect on the system (Table 2 ), contrary to that in case of $G=400 \mathrm{~W} / \mathrm{m}^{2}$ there is an important difference in the system parameters before and after optimization.

\section{CONCLUSION}

An optimal operation of a photovoltaic pumping system based on an Induction motor was described. The optimization criterion fixes the maximization of the motor efficiency, and where the extracted electric power is controlled by the chosen MPPT method. A comparative study was carried out on two systems: direct coupled and the optimized. The simulation results show that an increase of both the daily pumped quantity and pump efficiency are reached by the proposed approach. In addition, the proposed approach does not need two converters, it uses only a DC/AC converter. Also we deduced from this study that the optimization method has an important effect on the law levels of insulations where the photovoltaic system work away from its reference values.

PV Array Characteristics:

PV generator: 19 series panell. GTO136 - 80/2,

$A M=1.5 . P_{m}=80 \mathrm{~W}, V_{o c, r e f}=21.5 \mathrm{~V}, I_{s c}=4.97 \mathrm{~A}$,

$I_{\text {mpref }}=4.7 \mathrm{~A}, V_{\text {mpref }}=16.9 \mathrm{~V}, N_{\text {oct }}=45^{\circ} \mathrm{C}$,

$G_{r e f}=1000 \mathrm{~W} / \mathrm{m}^{2}, T_{r e f}=298^{\circ} \mathrm{K}$,

$\mu_{I_{s c}}=3 \times 10^{-3} \mathrm{~A} /{ }^{\circ} \mathrm{C}, \mu_{V_{o c}}=-82 \times 10^{-5} \mathrm{~V} /{ }^{\circ} \mathrm{C}$.

IM Motor Characteristics:

$P_{n}=1.5 \mathrm{KW}, f=50 \mathrm{~Hz}, I_{s n}=3.5 \mathrm{~A}, T e=12 \mathrm{~N} . \mathrm{m}$. $R=5.72 \Omega, L_{s}=0.462 \mathrm{H}, R_{r}=4.2 \Omega, L_{r}=0.462 \mathrm{H}$, $M=0.44 \mathrm{H}, J=0.0049 \mathrm{Kg} / \mathrm{m}^{2}, p=2$,

$f f=0.0009 \mathrm{Nms} / \mathrm{rad}, K_{r}=5.333 \times 10^{-4}(\mathrm{Nm})(\mathrm{s} / \mathrm{rad})^{2}$, $K_{p}=3.2 \times 10^{-4}(\mathrm{Nm})(\mathrm{s} / \mathrm{rad})^{3}$

Corrector Parameters PI (Speed, current, flux):

$K_{i v}=3.92, K_{p v}=0.2, K_{i \Phi}=50, K_{p \Phi}=2.73$,

$K_{i d}=3436.2, K_{p d}=11.46$.

\section{REFERENCES}

[1] SimOeS, M. G.-FRANCESCHETTI, N. N.: Arisc-Microcontroller Based Photovoltaic System for Illumination Applications, Proceeding of IEEE Applied Power Electronics Conference and Exposition 15 (2000)

[2] AKBABA, M.-AKBABA, M. C.: Dynamic Performance of a Photovoltaic Boost Converter Powered DC Motors-Pump System, In: Proceeding of IEEE International Conference, IEMDC99, 16, 1999.

[3] MATSUi, M.-KITANO, T.-XU, D.-YANG, Z.: A New Maximum Photovoltaic Power Tracking Control Scheme Based on Power Equilibrium at DC Link, Proceeding of IEEE Industry Applications Conference, 1999.

[4] SHRERThA, G. B.-GOEL, L.: A Study on Optimal Sizing of Stand Alone Photovoltaic Stations, IEEE Trans Energ Conv 13 No. 4 (1998), 373-377.

[5] SAMIN, J. et al: Optimal Sizing of Photovoltaic in Varied Climates, Solar Energy 6 No. 2 (1997), 97-107. 
[6] AKBABA, M. et al : Matching of Separately Excited DC Motor to Photovoltaic Generators for Maximum Power Output, Solar Energy 63 No. 6 (1998), 375-385.

[7] SAID, M. M. : Matching of DC Motor to Photovoltaic Generators for Maximum Daily Gross Mechanical Energy, IEEE Trans Energ Conv 3 No. 3 (1988), 465-471.

[8] WEINER, D.-LEVINSON, A.: Water Pumping Optimal Operation, Elect Mach Power Syst 24 No. 3 (1996), 277-288.

[9] APPELBAUM, J. : Starting and Steady State Characteristics of DC Motor Powered by Solar Cell Generator, IEEE Trans Energy Conv 1 No. 1 (1986), 17-25.

[10] APPELBAUM, J.-SARME, M. S. : The Operation of Permanent Magnet DC Motor Powered by Common Source of Solar Cells, IEEE Trans Energy Conv 4 No. 4 (1989), 635-642.

[11] SWAMY, C. L. P. et al : Dynamic Performance of a Permanent Magnet DC Motor Powered by a PV Array for Water Pumping, Solar Energy Mat Solar Cell 36 (995), 187-200.

[12] BAHT, S. R. et al: Performance Optimisation of Induction Motor-Pump using Photovoltaic Energy Source, IEEE Trans Ind App 23 No. 6 (1987), 995-1000.

[13] CHENNI, R.-MAKHLOUF, M. et al : Detailed Modelling Method for Photovoltaic Cell, Energy 32 (2007), 1724-1730.

[14] YAO, Y.-BUSTAMENTE, P.-RAMSHAW, R. S. : Improvement of induction Motor Drive Systems Supplied by Photovoltaic Arrays with Frequency Control, IEEE Trans Energ Conv 9 No. 2 (1994).

[15] JAHNS, T. M. : FluxWeakening Regime Operation of an Interior Permanent Magnet Synchronous Motor Drive, IEEE on IA No. 4 (July/Aug 1987), 681-689.

[16] KIN, J. M.-SUL, S. K. : Speed Control of Interior Permanent Magnet Synchronous Motor Drive for Flux Zeaking Operation 3in, Proc. IEEE IAS Annual Meeting mpp. 216-221, 199.

[17] BETKA, A.-MOUSSI, A.: Performance Optimization of a Photovoltaic Induction Motor Pumping System, Renewable Energy 29 (2004), 2167-2181.

[18] MIMOUNI, M. F.-DHIFAOUI, R.-BRUDNY, J. F.-ROGER, D.: Field-Oriented Control of Double-Star Induction
Machine, Int Journal System of Analysis Modelling Simulation (SAMS) ayr2000 37, 181-202.

[19] GRELLET, G.-CLERC, G.: Actionneurs Electriques, Principes Modèles Commande, Eyrolles, 1997.

[20] HAMROUNI, N.-JRAIDI, M.-CHERIF, A.-DHOUIB, A. : Measurements and Simulation of a PV Pumping Systems Parameters using MPPT and PWM Control Strategies, IEEE MELECON 2006, May 16-19, Benalmadena (Malaga), Spain.

Received 25 February 2010

Messaoud Makhlouf received the MS degrees from Mentouri University of Constantine. He is currently Assistant researcher in the Department of Electrical Engineering at the University of Constantine, Algeria, engaged in research. His interests are in the areas of renewable energy, modeling and simulation of photovoltaic cells, conversion analysis, and modeling of power converters. He now working on the domain of the photovoltaic systems connected to the grid.

Feyrouz Messai received the MS degrees from Mentouri University of Constantine. She is currently Assistant researcher in the Department of Electrical Engineering at the University of Constantine, Algeria, engaged in research. His interests are in the areas of simulation and motor optimization, energy conversion analysis, and modeling of power converters. She currently working on the use of switched reluctance machine in the renewable energy systems

Hocine Benalla received the BS, MS, and Doctorate Engineer degrees in power electronics, from the National Polytechnic Institute of Toulouse, France, respectively in 1981, 1984. In 1995, he received the Ph.D. degree in Electrical Engineering from University of Jussieu-Paris VI, France. Since 1996, he is with the department of Electrotechnics, at Constantine University Algeria, as a Professor. His current research field includes Active Power Filters, PWM Inverters, Electric Machines, and AC Drives.

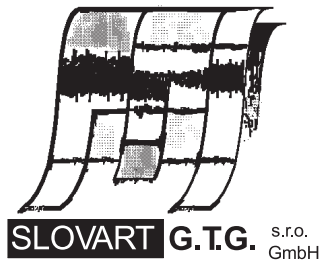

EXPORT - IMPORT
EXPORT - IMPORT

of periodicals and of non-periodically printed matters, books and CD-ROMs

Krupinská 4 PO BOX 152, 85299 Bratislava 5, Slovakia tel: ++421 263839 472-3, fax: ++421263839485 info@slovart-gtg.sk; http://www.slovart-gtg.sk

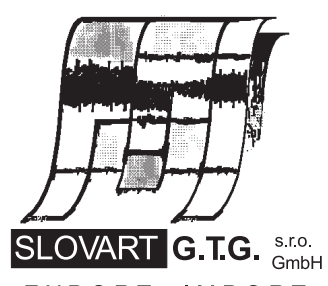

EXPORT - IMPORT 